Int. J. Electrochem. Sci., 12 (2017) 10177 - 10186

\title{
Electrochemically Reduced Graphene Oxide Modified Screen- Printed Electrodes for Sensitive Determination of Acetylsalicylic Acid
}

\author{
Chunzhi Zhao ${ }^{1}$ and Jihong Lin $^{2, *}$ \\ ${ }^{1}$ Department of Medicine, First Affiliated Hospital of Harbin Medical University, Harbin, 150001, \\ China \\ ${ }^{2}$ Pharmacy Intravenous Admixture Service, First Affiliated Hospital of Harbin Medical University, \\ Harbin, 150001, China \\ *E-mail: harbin_linjihong@yahoo.com
}

doi: $10.20964 / 2017.11 .03$

Received: 10 July 2017 / Accepted: 4 September 2017 / Published: 12 October 2017

In this report, the voltammetric detection of aspirin (ASA) was performed using an electrochemical sensor modified with a graphene-Nafion nanocomposite film. A Nafion graphene oxide-decorated glassy carbon electrode (GCE) was prepared using a facile drop-casting strategy followed by the reduction of graphene oxide on the surface of the GCE via an electrochemical technique. The electrochemically reduced graphene oxide (ER-GO)/Nafion screen-printed electrode (SPE) was finally fabricated and used for the detection of ASA.

Keywords: Reduced graphene oxide; Screen-printed electrode; Aspirin; Electrochemical determination; Human oral fluid

\section{FULL TEXT}

(C) 2017 The Authors. Published by ESG (www.electrochemsci.org). This article is an open access article distributed under the terms and conditions of the Creative Commons Attribution license (http://creativecommons.org/licenses/by/4.0/). 